\title{
Исследование физико-химической природы процессов, протекающих при регенерации алюмосиликатных адсорбентов на установках подготовки газа к транспорту
}

\author{
(C) 2021 Темердашев 3.А. ${ }^{1}$, Руденко А.В. ${ }^{2}$, Колычев И.А. ${ }^{2}$, Костина А.С. ${ }^{1}$ \\ ${ }^{I}$ Кубанский государственный университет, Краснодар \\ ${ }^{2}$ Краснодарский ЛПУМГ филиал ООО «Газпром трансгаз Краснодар», Краснодар
}

Поступила в редакцию 28.01.2021 г.

DOI: $10.17308 /$ sorpchrom.2021.21/3349

Работа посвящена физико-химическому исследованию процессов регенерации алюмосиликатных адсорбентов на установках подготовки природного газа к транспорту. Объектами исследования являлись природный газ, подаваемый в адсорбционную установку с адсорбентом, продукты его превращений, а также образующийся в процессе регенерации конденсат газовый стабильный. Определение компонентов в конденсате, образованном в адсорбционной установке с адсорбентом, проводили методом газовой хроматомасс-спектрометрии. Анализ компонентного состава нижней фракции сконденсированной жидкости осуществляли методом газожидкостной хроматографии. После прохождения природного газа через установку подготовки природного газа к транспорту идентифицировали вещества, которые отсутствовали в исходном составе - диметиловый эфир, диметилсульфид, тетраметилбензол, пентаметилбензол, гексаметилбензол и другие. Хроматографический анализ нижней фракции сконденсированной жидкости показал наличие в ней метанола и диметилового эфира. Количественную оценку содержания метанола в исследуемых фракциях проводили с использованием стандартных образцов метанола. Цель работы - изучение химических процессов, протекающих при регенерации алюмосиликатных адсорбентов, и конверсии метанола, извлеченного из природного газа на установках подготовки газа к транспорту. Присутствие метанола в продуктах очистки природного газа обусловлено его использованием в качестве ингибитора гидратообразования в технологии добычи газа, а наличие отсутствующих в исходном газе некоторых веществ объясняется химическими реакциями, протекающими в условиях высокотемпературной регенерации на установках подготовки газа к транспорту. Рассмотрены условия регенерации алюмосиликатных адсорбентов, обеспечивающих конверсию метанола в диметиловый эфир и метилирование сероводорода с образованием диметилсульфида. Изучена физико-химическая природа метилирования ароматических соединений, содержащихся в природном газе, и образования твердых алкиларенов. Установлено распределение адсорбированных компонентов в промышленных адсорбционных установках осушки природного газа. Оптимизация условий протекания описанных процессов позволила сократить количество вредных выбросов и уменьшить расходы топливного газа, расходуемого при работе стационарной установки термического обезвреживания. Данные процессы представляют практическую значимость, так как повышают экологичность технологического процесса.

Ключевые слова: природный газ, алюмосиликатный адсорбент, регенерация адсорбентов, установка подготовки газа к транспорту, конверсия метанола, диметиловый эфир, метилирование аренов.

\section{Введение}

Очистка природного горючего газа (ГГП) от паров воды и жидких углеводородов (ЖУВ) осуществляется, как пра- вило, с применением алюмосиликатных адсорбентов с заданными эксплуатационными характеристиками на установках подготовки газа к транспорту (УПГТ) 
адсорбционного типа, работающих в циклическом режиме «адсорбция - регенерация - охлаждение» [1]. Природный газ проходит через систему адсорберов, очищается от капельной влаги на адсорбентах защитного слоя (адсорбент силикагелевый микропористый влагостойкий - ACM ВС, силикагелевый водостойкий BASF KC-Trockenperlen WS, адсорбент на основе оксида алюминия НИАПAOC), а затем от паров воды и тяжелых углеводородов на адсорбентах основного слоя (АСМ и BASF KC-Trockenperlen H). Регенерацию отработанного насыщенного алюмосиликатного слоя осуществляют термической десорбцией компонентов при $280-290^{\circ} \mathrm{C}$ нагретым потоком природного газа. Адсорбированные компоненты переходят в газовую фазу из адсорбера в аппарат воздушного охлаждения (ABO). В ABO компоненты конденсируются с образованием двухслойной жидкости, верхний слой которой состоит, в основном, из углеводородов и образует газовый конденсат, а нижний из воды и метанола.

На стадии высокотемпературной регенерации в УПГТ возможно образование диметилового эфира (ДМЭ) за счет конверсии метанола в присутствии оксида алюминия в составе адсорбентов [2-4] (табл. 1). Мезопористые мезоструктурированные силикаты SBA-15 (Santa Barbara Amorphous) и MCF (Mesocelluar Foam), немодифицированные оксидом алюминия, не проявляют каталитической активности при $125-300^{\circ} \mathrm{C}$, атмосферном давлении и скорости потока 20 мл/мин. Конверсия метанола на модифицированных оксидом алюминия адсорбентах начинает протекать при $125^{\circ} \mathrm{C}$ и макси- мальна (80 \%) при $300^{\circ} \mathrm{C}$ [5].

Образующийся при конверсии метанола ДМЭ может выступать метилирующим агентом соединений, присутствующих в природном газе, в частности, в процессах метилирования сероводорода и ароматических углеводородов [6-10]. Такой способ можно рассматривать как решение проблемы утилизация метанола, находящегося в продуктах очистки природного газа, превращением его в ДМЭ в УПГТ адсорбционного типа, поэтому исследование этих вопросов становится очень актуальным.

Целью настоящей работы является изучение химических процессов, протекающих при регенерации алюмосиликатных адсорбентов, и конверсии метанола, извлеченного из природного газа на установках подготовки газа к транспорту.

\section{Экспериментальная часть}

Объекты исследования и реактивы. Объектами исследования являлись природный газ, подаваемый в адсорбционную установку с адсорбентом, а также образующийся в процессе регенерации конденсат газовый стабильный. Изучение процессов, протекающих в УПГТ на стадии регенерации, проводили с использованием силикагелей BASF KCTrockenperlen (Германия) и отечественных силикагелевых микропористых адсорбентов АСМ, СТО 61182334-0042011.

Количественное определение метанола проводили с использованием стандартных образцов метанола (ГСО 84612003).

Таблица 1. Содержание оксида алюминия в алюмосиликатных адсорбентах, используемых на УПГТ ПАО «Газпром» [1]

Table 1. The content of aluminium oxide in aluminosilicate adsorbents used in the gas treatment unit of PAO Gazprom [1]

\begin{tabular}{|c|c|c|}
\hline Марка адсорбента & Назначение & Концентрация $\mathrm{Al}_{2} \mathrm{O}_{3}, \%$ \\
\hline KC-Trockenperlen WS & Защитный слой & $3.5 \pm 0.9$ \\
\hline KC-Trockenperlen H & Основной слой & $3.1 \pm 0.6$ \\
\hline ACM BC & Защитный слой & $13.2 \pm 0.4$ \\
\hline ACM & Основной слой & $3.9 \pm 0.3$ \\
\hline \multicolumn{2}{|r|}{}
\end{tabular}


Оборудование и условия хроматографирования. Хроматографическое определение компонентов в конденсате, образованном на УПГТ адсорбционного типа, проводили на газовом хроматограde Shimadzu GC-2010 c мaccспектрометрическим детектором GCMSQP2010 Plus. Разделение аналитов осуществляли на кварцевой капиллярной колонке Quadrex 5MS (30 м×0.25 мм, 0.25 мкм) при сканировании по полному ионному току в интервале $\mathrm{m} / \mathrm{z}$ 29-400. Температурный режим: $35^{\circ} \mathrm{C}$ в течение 1 мин, подъем температуры до $100^{\circ} \mathrm{C}$ со скоростью $5^{\circ} \mathrm{C} / \mathrm{мин,} \mathrm{далее} \mathrm{-} \mathrm{до} 285^{\circ} \mathrm{C}$ со скоростью $5^{\circ} \mathrm{C} /$ мин. Температура ионного источника $-250^{\circ} \mathrm{C}$, температура интерфейса $-280^{\circ} \mathrm{C}$, температура испарителя $-270^{\circ} \mathrm{C}$. Объем вводимой пробы 1 мкл, время анализа 45 мин. В качестве газа-носителя использовали гелий, расход которого составил $0.65 \mathrm{~cm}^{3} / \mathrm{Mин,} \mathrm{де-}$ ление потока 1:50. Идентификацию компонентов проводили сопоставлением полученных масс-спектров с данными библиотеки NIST-17.

Анализ неуглеводородной (нижней) фракции сконденсированной жидкости осуществляли на газовом хроматографе «Кристалл 2000М» с использованием кварцевой капиллярной колонки НРFFAP (50 м $\times 0.32$ мм $\times 0.52$ мкм $)$ и пламенно-ионизационным детектором (ПИД). Температурная программа про- ведения анализа: $70^{\circ} \mathrm{C}-10$ мин; повышение температуры до $240^{\circ} \mathrm{C}$ со скоростью $5^{\circ} \mathrm{C} /$ мин. Температура детектора $250^{\circ} \mathrm{C}$, температура испарителя $-220^{\circ} \mathrm{C}$, скорость газа-носителя (азота) $-16 \mathrm{~cm} / \mathrm{c}$, расход водорода в ПИД - $25 \mathrm{~cm}^{3} /$ мин, расход воздуха в ПИД - $250 \mathrm{~cm}^{3} /$ мин. Объем пробы - 1 мкл, время анализа 40 мин, деление потока 1:20.

\section{Обсуждение результатов}

При установлении компонентного состава природного газа и газового конденсата, образованного на УПГТ адсорбционного типа, были выявлены и идентифицированы вещества, которые отсутствовали в исходном составе природного газа - ДМЭ, диметилсульфид, тетраметилбензол, пентаметилбензол, гексаметилбензол и др. (табл. 2).

Хроматографический анализ неуглеводородной фракции сконденсированной жидкости показал наличие в ней метанола и ДМЭ (рис. 1). Присутствие метанола в продуктах очистки природного газа обусловлено его использованием в качестве ингибитора гидратообразования в технологии добычи газа $[11,12]$, а наличие отсутствующих в исходном газе компонентов (ДМЭ, диметилсульфида, тетраметилбензола, пентаметилбензола, гексаметилбензола и др.) свидетельствует о протекании ряда химических реакций при работе УПГТ.

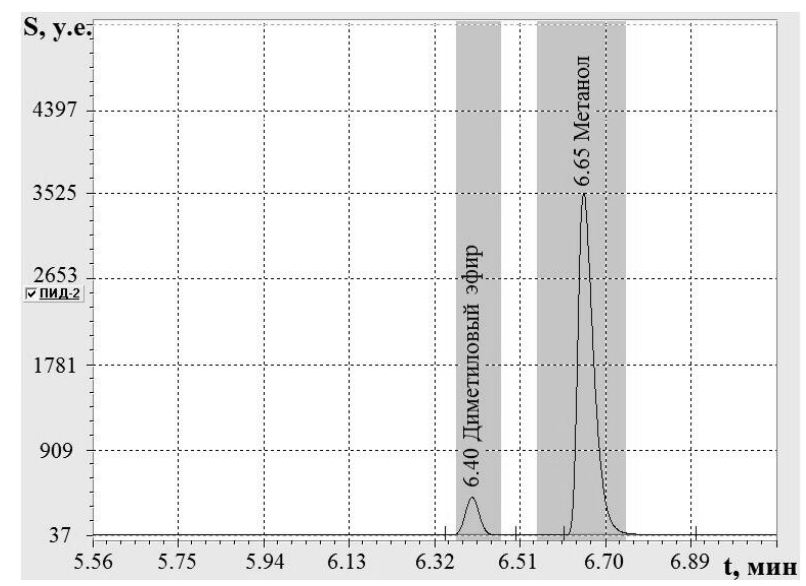

Рис. 1. Фрагмент хроматограммы неуглеводородной фазы продуктов очистки природного газа на УПГТ адсорбционного типа

Fig. 1. Fragment of the chromatogram of the non-hydrocarbon phase of the natural gas purification products in a gas treatment unit 
Таблица 2. Компонентные составы природного газа и конденсата газового стабильного из установки на алюмосиликатных адсорбентах

Table 2. Component compositions of natural gas and stable gas condensate from a unit on aluminosilicate adsorbents

\begin{tabular}{|c|c|c|}
\hline \multirow[t]{2}{*}{ Компоненты } & Природный газ & $\begin{array}{c}\text { Конденсат газовый ста- } \\
\text { бильный }\end{array}$ \\
\hline & \multicolumn{2}{|c|}{ Концентрация, \% масс. } \\
\hline этан & 3.54 & 0.02 \\
\hline H-пропан & 1.53 & 0.21 \\
\hline диметиловый эфир & отс. & 0.58 \\
\hline изо-бутан & 0.32 & 0.27 \\
\hline метанол & 0.04 & 0.01 \\
\hline н-бутан & 0.31 & 0.50 \\
\hline диметилсульфид & отс. & 0.09 \\
\hline изо-пентан & 0.07 & 0.85 \\
\hline н-пентан & 0.05 & 1.01 \\
\hline 2-метилпентан & 0.02 & 1.96 \\
\hline 3-метилпентан & 0.01 & 1.10 \\
\hline н-гексан & 0.01 & 3.17 \\
\hline метилциклопентан & 0.005 & 2.52 \\
\hline бензол & 0.001 & 5.37 \\
\hline циклогексан & 0.001 & 6.26 \\
\hline н-гептан & 0.004 & 6.03 \\
\hline метилциклогексан & 0.005 & 16.71 \\
\hline триметилциклопентан & менее 0.001 & 1.56 \\
\hline метилбензол & менее 0.001 & 6.91 \\
\hline 2-метилгептан & менее 0.001 & 1.44 \\
\hline гексаметилбензол & отс. & 0.44 \\
\hline н-октан & 0.001 & 2.58 \\
\hline н-нонан & менее 0.001 & 0.88 \\
\hline о-, м-, п-ксилолы & менее 0.001 & 0.03 \\
\hline 1,3-диметилциклогексан & отс. & 3.61 \\
\hline
\end{tabular}

Для объяснения образующегося состава газового конденсата из УПГТ проводили возможные аналогии работы адсорберов и колоночной фронтальной хроматографии на силикагеле. Адсорбционная активность различных веществ по отношению к силикагелю часто отличается. Это объясняется тем, что вещества с более высокой активностью вытесняют другие компоненты. Для силикагеля известен ряд Снайдера, в котором относительные значения элюирующей силы растворителей располагаются в порядке возрастания в следующей последовательности: н-пентан < н-гексан < изооктан $<$ циклогексан $<$ бензол $<$ ме- танол < вода [11]. Если проводить аналогию с рядом Снайдера, то в рассматриваемом нами случае сначала в адсорбере должна скапливаться вода, за ней метанол, арены, цикланы и алканы. Проведенные экспериментальные исследования позволили определить вещества, образующиеся после пропускания природного газа через слой адсорбента, что подтвердило последовательное вытеснение компонентов из адсорбера парами воды (табл. 3). Установленное распределение адсорбированных компонентов в адсорбционной колонне схематично отображено на рис. 2. 
Таблица 3. Компоненты, образующиеся на выходе после пропускания природного газа через адсорбционную колонну [1]

Table 3. Components formed at the outlet after passing natural gas through an adsorption column [1]

\begin{tabular}{|c|c|c|c|c|c|c|c|}
\hline \multirow{2}{*}{$\begin{array}{c}\text { Работа ад- } \\
\text { сорберов, } \\
\text { мин }\end{array}$} & \multirow{2}{*}{$\begin{array}{c}\text { Расход } \\
\text { газа, } \\
\text { тыс. } \text { м }^{3} / \text { }\end{array}$} & $\mathrm{C}_{6} \mathrm{H}_{6}$ & $\mathrm{C}_{8} \mathrm{H}_{18}$ & $\mathrm{H}_{2} \mathrm{~S}$ & $\left(\mathrm{CH}_{3}\right)_{2} \mathrm{~S}$ & ДМЭ & Метанол \\
\hline & & \multicolumn{2}{|c|}{ \% молярн. } & \multicolumn{2}{|c|}{$\mathrm{M \Gamma} / \mathrm{M}^{3}$} & \multicolumn{2}{|c|}{ \% молярн. } \\
\hline 70 & 218 & отс. & отс. & 0.031 & отс. & отс. & отс. \\
\hline 140 & 213 & отс. & отс. & 0.031 & отс. & отс. & OTc. \\
\hline 210 & 219 & отс. & 0.0016 & 0.071 & отс. & отс. & отс. \\
\hline 280 & 208 & 0.0003 & 0.0034 & 0.130 & 1.75 & 0.0066 & отс. \\
\hline 350 & 217 & 0.0010 & 0.0040 & 0.950 & 2.70 & 0.0128 & отс. \\
\hline 420 & 223 & 0.0014 & 0.0040 & 0.095 & 3.70 & 0.0167 & OTc. \\
\hline 490 & 215 & 0.0014 & 0.0039 & 0.085 & 4.00 & 0.0176 & отс. \\
\hline 560 & 218 & 0.0014 & 0.0039 & 0.096 & 3.69 & 0.0176 & OTc. \\
\hline 630 & 220 & 0.0013 & 0.0039 & 1.900 & 10.15 & 0.0176 & OTc. \\
\hline 700 & 224 & 0.0012 & 0.0037 & 1.990 & 9.10 & 0.0157 & 0.002 \\
\hline
\end{tabular}

Каталитические свойства алюмосиликатных адсорбентов, применяемых в УПГТ, ранее тестировали на экспериментальной лабораторной установке проточного типа [1]. При этом отмечалась их высокая активность в процессе конверсии метанола в ДМЭ при $290^{\circ} \mathrm{C}$. При образовании ДМЭ из метанола и метилировании аренов и сероводорода возможны два механизма реакции - acсоциативный и диссоциативный [13]. При высоких концентрациях метанола на алюмосиликатных адсорбентах на стадии регенерации УПГТ сначала образуется ДМЭ, который метилирует ароматическое кольцо, а в случае низких концентраций метанола алкилирующим агентом является непосредственно сам метанол. С повышением температуры регенерации компоненты десорбируются и движутся вдоль адсорбента, при этом углеводороды движутся быстрее, поэтому метанол не может вступить с ними в реакцию, и наиболее вероятным является механизм алкилирования аренов в адсорбционной колонне диметиловым эфиром, который обладает большей подвижностью на алюмосиликатных адсорбентах, чем метанол. Проведенная идентификация компонентов, образующихся после пропускания природного газа через адсорбционную колонну, показала наличие в адсорбционной колонне, наряду с ДМЭ, бензола, толуола, сероводорода и диметилсульфида (табл. 3). Данный факт, по-видимому, можно объяснить возможностью протекания ряда химических реакций.

С учетом полученных данных можно предположить появление побочных про-

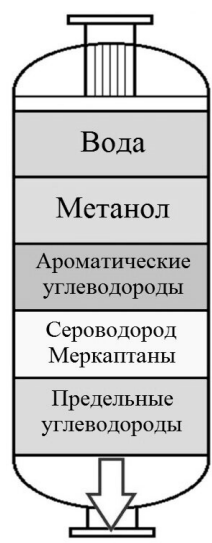

Рис. 2. Схематическое распределение компонентов природного газа в адсорбционной колонне

Fig. 2. Schematic distribution of natural gas components in an adsorption column 
дуктов за счет протекания ряда превращений при высокотемпературной регенерации промышленных адсорбентов:

1. Конверсия метанола с образованием ДМЭ:

$$
2 \mathrm{CH}_{3} \mathrm{OH} \rightarrow \mathrm{CH}_{3}-\mathrm{O}-\mathrm{CH}_{3}+\mathrm{H}_{2} \mathrm{O} \text { (1) }
$$

2. Метилирование бензола ДМЭ с образованием гексаметилбензола:

$\mathrm{C}_{6} \mathrm{H}_{6}+3 \mathrm{CH}_{3}-\mathrm{O}-\mathrm{CH}_{3} \rightarrow \mathrm{C}_{6}\left(\mathrm{CH}_{3}\right)_{6}+3 \mathrm{H}_{2} \mathrm{O}$ (2)

3. Метилирование сероводорода ДМЭ с образованием диметилсульфида:

$$
\mathrm{H}_{2} \mathrm{~S}+\mathrm{CH}_{3}-\mathrm{O}-\mathrm{CH}_{3} \rightarrow\left(\mathrm{CH}_{3}\right)_{2} \mathrm{~S}+\mathrm{H}_{2} \mathrm{O} \text { (3) }
$$

\section{Заключение}

Изучены химические процессы, протекающие при регенерации алюмосиликатных адсорбентов при $280-290^{\circ} \mathrm{C}$, и конверсии метанола, извлеченного из природного газа на установках подго- товки газа к транспорту. Рассмотрены условия регенерации алюмосиликатных адсорбентов, обеспечивающих конверсию метанола в диметиловый эфир и метилирование сероводорода с образованием диметилсульфида. Изучена физико-химическая природа метилирования ароматических соединений, содержащихся в природном газе, и образования алкиларенов. Оптимизация условий протекания описанных процессов позволит сократить количество вредных отходов и уменьшить расходы топливного газа, расходуемого при работе стационарной установки термического обезвреживания, в которой утилизируется неуглеводородная фракция продуктов очистки природного газа.

Исследования проводились в рамках выполнения Госзадания Минобрнауки РФ, проект № FZEN-2020-0022, с использованием научного оборудования ЦКП «Эколого-аналитический иееттр» Кубанского госуниверситета

\section{Список литературы}

1. Темердашев 3.А., Руденко А.В., Колычев И.А., Костина А.С. // Экология и промышиленность России. 2019. Т. 23. № 11. С. 4-9.

2. Rashidi H., Hamoule T., Reza Khosravi Nikou M., Shariati A. // Iranian Journal of Oil \& Gas Science and Technology. 2013. Vol. 2. No 4. pp. 67-73.

3. Catizzone E., Migliori M., Aloise A., Lamberti R. et al. // Journal of Chemistry. 2019. Vol. 2019. pp. 1-9.

4. Bateni H., Able C. // Catalysis in Industry. 2019. Vol. 11. No 1. pp. 7-33.

5. Macina D., Piwowarska Z., Tarach K., Góra-Marek K., Ryczkowski J., Chmielarz L. // Materials Research Bulletin. 2016. Vol. 74. pp. 425-435.

6. Fečík M., Plessow P.N., Studt F.A. // ACS Catalysis. 2020. Vol. 10. No 15. pp. 8916-8925.

7. DeLuca M., Kravchenko P., Hoffman A., Hibbitts D. // ACS Catalysis. 2019. Vol. 9. No 7. pp. 6444-6460.
8. De Wispelaere K., Martinez-Espin J.S., Hoffmann M.J., Svelle S. et al. // Catalysis Today. 2018. Vol. 312. pp. 35-43.

9. Martinez-Espin J.S., De Wispelaere K., Erichsen M.W., Svelle S. et al. // Journal of Catalysis. 2017. Vol. 349. pp. 136-148.

10. Hill I., Malek A., Bhan A. // ACS Catalysis. 2013. Vol. 3. No 9. pp. 1992-2001.

11. Kvamme B., Selvåg, J., Saeidi N., Kuznetsova T. // Physical Chemistry Chemical Physics. 2018. Vol. 20. No 34. pp. 2196821987.

12. Шиповалов А.Н., Земенкова М.Ю., Шпилевой В.А., Александров М.А. и др. // Современные проблемы науки и образования. 2015. № 2-2. С. 31-38.

13. Ivanova I.I., Pomakhina E.B., Borodina I.B., Rebrov A.I. et al. // Studies in Surface Science and Catalysis. 2004. Vol. 154. pp. 22212227. 


\title{
Investigation of the physicochemical nature of the processes occurring during the regeneration of aluminosilicate adsorbents in gas treatment units
}

\author{
(C) 2021 Temerdashev Z.A. ${ }^{1}$, Rudenko A.V. ${ }^{2}$, Kolychev I.A. ${ }^{2}$, Kostina A.S. ${ }^{1}$ \\ ${ }^{1}$ Kuban State University, Krasnodar, Russian Federation \\ ${ }^{2}$ Krasnodar Linear Production Department of Main Gas Pipelines branch \\ of OOO Gazprom transgaz Krasnodar, Krasnodar, Russian Federation
}

\begin{abstract}
The study is devoted to the physicochemical investigation of the processes of regeneration of aluminosilicate adsorbents in gas treatment units. The objects of the study were natural gas supplied to the adsorption unit with an adsorbent, the products of its transformations, as well as the stable gas condensate formed during the regeneration process. The determination of the components in the condensate formed in the adsorption unit with the adsorbent was carried out by gas chromatography-mass spectrometry. The analysis of the component composition of the lower fraction of the condensed liquid was carried out by gas-liquid chromatography. After passing the natural gas through the gas treatment unit, substances that were absent in the initial composition were identified: dimethyl ether, dimethyl sulphide, tetramethylbenzene, pentamethylbenzene, hexamethylbenzene, and others. Chromatographic analysis of the bottom fraction of the condensed liquid showed the presence of methanol and dimethyl ether in it. The quantitative assessment of the methanol content in the investigated fractions was carried out using standard methanol samples. The purpose of this study was the investigation of he chemical processes occurring during the regeneration of aluminosilicate adsorbents and the conversion of methanol extracted from natural gas in gas treatment units. The presence of methanol in the products of natural gas purification is due to its use as an inhibitor of hydrate formation in gas production technology, and the presence of some substances absent in the initial gas is explained by chemical reactions occurring under conditions of high-temperature regeneration in gas treatment units. The conditions for the regeneration of aluminosilicate adsorbents providing the conversion of methanol to dimethyl ether and methylation of hydrogen sulphide with the formation of dimethyl sulphide are considered. The physicochemical nature of methylation of aromatic compounds contained in natural gas and the formation of solid alkylarenes has been studied. The distribution of adsorbed components in industrial adsorption units for natural-gas dehydration has been established. Optimization of the conditions for the described processes allowed reducing the amount of harmful emissions and reduce the consumption of fuel gas consumed during the operation of a stationary thermal treatment unit. These processes are of practical importance, as they increase the environmental friendliness of the technological process.
\end{abstract}

Keywords: natural gas, aluminosilicate adsorbent, adsorbent regeneration, gas treatment unit, methanol conversion, dimethyl ether, methylation of arenes.

\section{References}

1. Temerdashev Z.A., Rudenko A.V., Kolychev I.A., Kostina A.S, Ecology and Industry of Russia, 2019, Vol. 23, No 11, pp. 4-9.

2. Rashidi H., Hamoule T., Reza Khosravi Nikou M., Shariati A., Iranian Journal of Oil \& Gas Science and Technology, 2013, Vol. 2, No 4, pp. 67-73. doi: 10.22050/ijogst.2013.4797.

3. Catizzone E., Migliori M., Aloise A., Lamberti R. et al., Journal of Chemistry, 2019, Vol. 2019, pp. 1-9. doi: 10.1155/2019/3084356.

4. Bateni H., Able C. // Catalysis in Industry, 2019, Vol, 11, No 1, pp. 7-33. doi: 10.1134/S2070050419010045.

5. Macina D., Piwowarska Z., Tarach K., Góra-Marek K. et al., Materials Research Bul- letin, 2016, Vol. 74, pp. 425-435. doi: 10.1016/j.materresbull.2015.11.018.

6. Fečík M., Plessow P.N., Studt F., ACS Catalysis, 2020, Vol. 10, No 15, pp. 8916-8925. doi: 10.1021/acscatal.0c02037.

7. DeLuca M., Kravchenko P., Hoffman A., Hibbitts D., ACS Catalysis, 2019, Vol. 9, No 7, pp. 6444-6460. doi: 10.1021/acscatal.9b00650.

8. De Wispelaere K., Martinez-Espin J.S., Hoffmann M.J., Svelle S. et al., Catalysis Today, 2018, Vol. 312, pp. 35-43. doi: 10.1016/j.cattod.2018.02.042.

9. Martinez-Espin J.S., De Wispelaere K., Erichsen M.W., Svelle S. et al., Journal of Catalysis, 2017, Vol. 349, pp. 136-148. doi: 10.1016/j.jcat.2017.03.007.

10. Hill I., Malek A., Bhan A., ACS Catalysis, 2013, Vol. 3, No 9, pp. 1992-2001. doi: $10.1021 / \operatorname{cs} 400377 \mathrm{~b}$. 
11. Kvamme B., Selvåg, J., Saeidi N., Kuznetsova T., Physical Chemistry Chemical Physics, 2018, Vol. 20, No 34, pp. 21968-21987. doi: 10.1039/C8CP02447B.

12. Shipovalov A.N., Zemenkova M.Y., Shpilevoj V.A., Aleksandrov M.A. et al., Sov-

Темердашев Зауаль Ахлоович - заведующий кафедрой аналитической химии, д.х.н., Кубанский государственный университет, Краснодар

Руденко Александр Валентинович - заместитель начальника Краснодарского ЛПУМГ филиала ООО «Газпром трансгаз Краснодар», ООО «Газпром трансгаз Краснодар», Краснодар

Колычев Игорь Алексеевич - начальник химико-аналитической лаборатории Краснодарского ЛПУМГ филиала ООО «Газпром трансгаз Краснодар», к.х.н., ООО «Газпром трансгаз Краснодар», Краснодар

Костина Анна Сергеевна - аспирант 1 года обучения кафедры аналитической химии, Кубанский государственный университет, Краснодар remennye problemy nauki $i$ obrazovaniya, 2015, No 2-2, pp. 31-38.

13. Ivanova I.I., Pomakhina E.B., Borodina I.B., Rebrov A.I. et al., Studies in Surface Science and Catalysis, 2004, Vol. 154, pp. 22212227. doi: 10.1016/S0167-2991(04)80479-8.

Temerdashev Zaual A. - doctor of chemical sciences, professor and the Head Department of Analytical Chemistry, Kuban State University, Krasnodar, e-mail: temza@kubsu.ru

Rudenko Alexander V. - Deputy Head of the Krasnodar LPMGP branch of Gazprom Transgaz Krasnodar, LLC «Gazprom transgaz Krasnodar», Krasnodar, e-mail: av.rudenko@tgk.gazprom.ru

Kolychev Igor A. - Head of the Chemical Analytical Laboratory of the Krasnodar LPMGP branch of Gazprom Transgaz Krasnodar, Ph.D. (chemistry), LLC «Gazprom transgaz Krasnodar», Krasnodar, email: krim-expert@yandex.ru

Kostina Anna S. - postgraduate of the Department of Analytical Chemistry, Kuban State University, Krasnodar, e-mail: annakostina0@gmail.com 